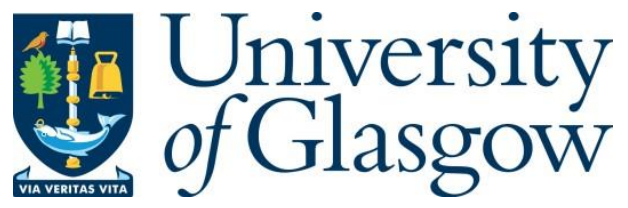

Shameem, U., Ur-Rehman, M., Abbasi, Q. H. and Qaraqe, K. (2016) A Low Profile Penta-band Antenna for Portable Devices. 2016 International Workshop on Antenna Technology (iWAT), Cocoa Beach, FL, USA, 28 Feb - 2 Mar 2016. pp. 174-177. ISBN

9781509002672 (doi:10.1109/IWAT.2016.7434835)

This is the author's final accepted version.

There may be differences between this version and the published version. You are advised to consult the publisher's version if you wish to cite from it.

http://eprints.gla.ac.uk/141429/

Deposited on: 30 June 2017

Enlighten - Research publications by members of the University of Glasgow http://eprints.gla.ac.uk33640 


\title{
A Low Profile Penta-band Antenna For Portable Devices
}

\author{
Usama Shameem ${ }^{1}$, Masood Ur-Rehman ${ }^{1}$, Qammer Hussain Abbasi ${ }^{2}$ and Khalid Qaraqe ${ }^{2}$ \\ ${ }^{1}$ Centre for Wireless Research, University of Bedfordshire, Luton LU1 3JU (UK) \\ ${ }^{2}$ Texas A \& M University at Qatar
}

\begin{abstract}
Recent years have seen a rapid growth of portable wireless communication systems. Limited form factor and operation at multiple frequencies of these devices require novel solutions of efficient embedded antennas. It has increased the demand of microstrip patch antennas due to their inherent properties of being low profile, simple design, small size and ease of fabrication and integration. Miniaturisation requirements have seen rise of multiband patch antennas. This paper presents the design and analysis of a novel multiband microstrip patch antenna. The antenna consists of a rectangular slot with two Eshaped stubs on both of its sides. An inverted T-shaped stub is present on the upper side of the slot while an I-shaped stub is there on the bottom side. A T-shaped feeding line feeds the antenna. The slot, stubs and feed collectively produce five frequency bands centred at 1.5 GHz, 2.2 GHz, 3.1 GHz, 4.2 GHz and $5.3 \mathrm{GHz}$ for LTE/4G/5G, WiBro/WiMax, Satcomm and WLAN applications. The antenna offers small size, good impedance bandwidth and high gain at all operating frequencies.
\end{abstract}

Keywords-Multiband antenna, Patch antenna, Slot antenna, LTE/4G/5G, WLAN, Portable devices.

\section{INTRODUCTION}

7 he wireless communication systems have 1 experienced a rapid growth in recent years. Increasing demand of portability of these systems also brings size restrictions for the device. It also inflicts size limitation on the integrated antenna making low profile, miniature but efficient antenna a basic requirement for these applications [1]. Moreover, provision of multiple technologies including GSM, LTE, 4G/5G, Wi-Fi, GPS, etc. necessitates multiple antennas. It results in increased size of the device. Single antenna operating at different frequencies appeared to be an efficient method to overcome this problem. In order to achieve this, multiband antennas were introduced [1]-[2].

Microstrip patch antennas offer benefits of low complexity, cost effectiveness, high flexibility, lightweight and small size [3]. They also have advantages of ease of design, fabrication and integration to the overall system. They come in different types and have varying structures but most of the geometries are variations of basic rectangular, circular and triangular patch design [3]. These features make the microstrip patch antennas a popular choice for portable devices requiring a single multiband antenna [4].

Various techniques were used to design a multiband antenna that can operate at different frequency bands. These techniques include thickening of patch, adding slots in ground plane and using shorting pins [5]. A planar dual-band monopole antenna has been proposed in [6]. Two frequency bands at $2.4 \mathrm{GHz}$ and $3.4 \mathrm{GHz}$ are generated for WiMAX applications using radiator of antenna, which is a short stem between two branches. The antenna is tunable and frequency tuning is obtained by applying reverse bias voltage across a varactor. The varactor is placed between the stem and one branch of the radiating patches. The biasing circuit consists of two radio frequency choke resistors and an L-shaped stub.

A planar multiband dipole antenna having multiframe Lslot loaded with a single microstrip linehas been discussed in [7]. The multiband operation at five wireless wide area network frequencies is achieved by forming LC resonators through a multiframe L-slot on a host dipole. The dipole is also loaded with a single microstrip line to generate a couple of shunts and series of capacitive gaps with an inductive strip.

Cho et al. have proposed a multiband antenna composed of a U-shaped loop, an inserted open-end T-shaped slot, and fed by microstrip coupling. The antenna uses three types of resonant modes including loop mode, slot mode, and monopole mode. The antenna operates at GSM800, DCS, PCS, UMTS and LTE bands [8].

A multiband printed planar inverted-F antenna for GSM900/1800 operation has been proposed in [9]. The antenna uses its one-eighth-wavelength mode as the fundamental resonant mode. The antenna comprises of two radiating strips of and is fed using a coupling feed.

A metamaterial-loaded rectangular monopole antenna design for WLAN and WiMAX applications has been studied by $\mathrm{He}$ et al. [10]. The monopole resonates at $5.2 \mathrm{GHz}$. Etching of an inverted-L slot produces a second resonance at $4.1 \mathrm{GHz}$ while the addition of the metamaterial reactive loading has created a third resonance at $2.4 \mathrm{GHz}$ band.

The design of a multiband patch antenna loaded with complementary split-ring resonators and reactive impedance surface is presented in [11]. The complementary split-ring resonators are incorporated on the patch as a shunt LC resonator and provide the low resonance frequency. Using the two-dimensional metallic patches that are printed on a metalgrounded substrate makes the reactive impedance surface.

A triple-band bow-tie monopole antenna fed through a coplanar waveguide has been proposed by Ming et al. [12]. The design uses multiple bent monopoles generated by etching slots of different lengths in a bow-tie patch for WLAN/WiMAX/LTE operation. 
Falade et al. have proposed a circular polarised antenna for multiband GPS receivers using multistacked patch approach [13]. The three stacked patches with a slit and symmetry I-slot are fed through a single coaxial probe. The antenna operates at L1 (1.575 GHz), L2 (1.227 GHz) and L5 (1.176 GHz) frequency bands with a minimum axial ratio of $0.51 \mathrm{~dB}$. Combination of a microstrip patch, two rings and a slot fed through an offset coaxial probe is used in [14] to realise a multiband antenna. The antenna covers GPS, 4G/LTE/CDMA, and Wi-Fi frequency bands.

A quad-band antenna design for GPS, WiMAX and WLAN applications has been studied in [15]. The antenna consists of rectangular slot, a feeding patch that is T-shaped, a stub that is inverted T-shaped and two E-shaped stubs. Two resonance bands are produced by the harmonics of the T-shaped feed patch while the other two harmonic frequencies are tuned independently by using double-folded stub in the feed patch.

Though successfully achieving a multiband operation, most of the discussed techniques here have demerits of complex design, low gain and low efficiency. It necessitates further research and optimum multiband antenna solutions. In this paper, design of a novel multiband antenna is proposed. The proposed antenna offers penta-band operation with miniaturised dimensions as compared to the design discussed in [Cao]. The antenna consists of a rectangular slot, a Tshaped feed patch, an inverted T-shaped stub, an I-shaped stub and two E-shaped stubs. It operates at five frequency bands covering $1.5 \mathrm{GHz}, 2.2 \mathrm{GHz}, 3.1 \mathrm{GHz}, 4.2 \mathrm{GHz}$ and $5.3 \mathrm{GHz}$ for $\mathrm{LTE} / 4 \mathrm{G} / 5 \mathrm{G}$, WiBro/WiMax, Satcomm and WLAN operation with high gain and good efficiency values.

Following the introduction in Section I, the paper is organised in three sections. Section II presents the structural details of the antenna. Section III discusses the results and presents detailed analysis of the antenna operation. Conclusions are drawn in Section IV.

\section{ANTENNA DESIGN}

TABLE I. PROPOSED ANTENNA DIMENSIONS (IN MILIMETERS)

\begin{tabular}{|c|c|c|c|}
\hline Dimension & $\begin{array}{c}\text { Value } \\
(\mathrm{mm})\end{array}$ & Dimension & $\begin{array}{c}\text { Value } \\
(\mathrm{mm})\end{array}$ \\
\hline L1 & 48 & $\mathrm{~W} 1$ & 18 \\
\hline L2 & 21.6 & $\mathrm{~W} 2$ & 1 \\
\hline L3 & 29 & $\mathrm{~W} 3$ & 0.3 \\
\hline L4 & 4.3 & $\mathrm{~W} 4$ & 3.6 \\
\hline L5 & 12 & $\mathrm{~W} 5$ & 20 \\
\hline L6 & 5.5 & $\mathrm{~W}$ & 1 \\
\hline L7 & 4 & $\mathrm{~W}_{\mathrm{S}}$ & 44 \\
\hline L8 & 3.8 & $\mathrm{~W}_{f}$ & 1.76 \\
\hline L9 & 1.75 & $\mathrm{~L}_{\mathrm{S}}$ & 56 \\
\hline L10 & 2 & $\mathrm{~g}$ & 3 \\
\hline L11 & 7 & $\mathrm{~g} 2$ & 0.4 \\
\hline L12 & 9.75 & $\mathrm{~S}_{\mathrm{S}}$ & 0.8 \\
\hline L13 & 22 & $\varepsilon_{\mathrm{r}}$ & 3.5 \\
\hline L14 & 2 & $\tan \delta$ & 0.004 \\
\hline
\end{tabular}

The antenna consists of a rectangular slot having dimensions $\mathrm{L} 1 \times \mathrm{W} 1=48 \times 18 \mathrm{~mm}^{2}$. The rectangular slot has four stubs. One Inverted T-shaped stub is present on the upper side of the slot. Two E- shaped stubs are present on both sides of the slot. One more I shaped stub is present on bottom of the rectangular slot. The E-shaped stubs are extended on both sides and double folded to get additional resonance frequency. The patch is fed by a $50 \mathrm{ohm}$ microstrip feed line etched on the lower side of the substrate. It is T-shaped with a width of $\mathrm{W}_{f}=1.76 \mathrm{~mm}$ to achieve an impedance of $50 \mathrm{ohms}$. Steps are used on both sides of the feed line to improve the impedance matching. The substrate has a relative permittivity of 3.5 and a thickness of $0.8 \mathrm{~mm}$. The loss tangent is at 0.004 . The dimensions of the proposed multiband antenna are summarised in Table 1 while the geometrical structure is shown in Fig. 1.

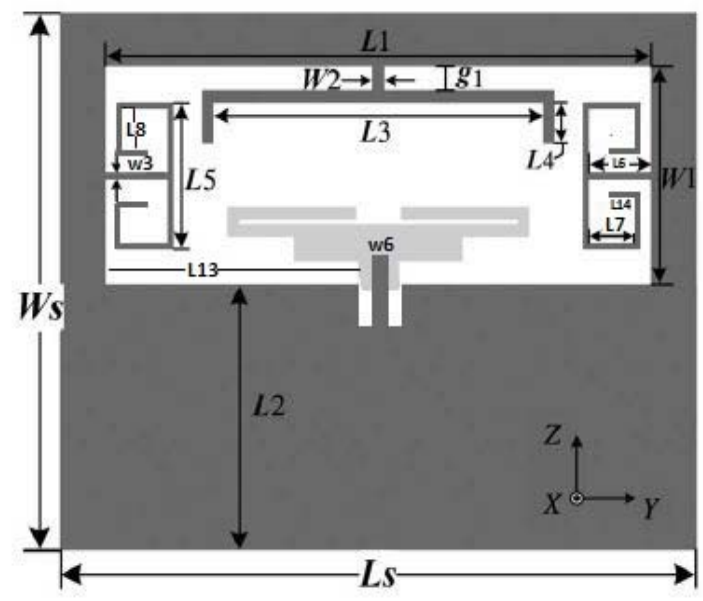

(a) Top view

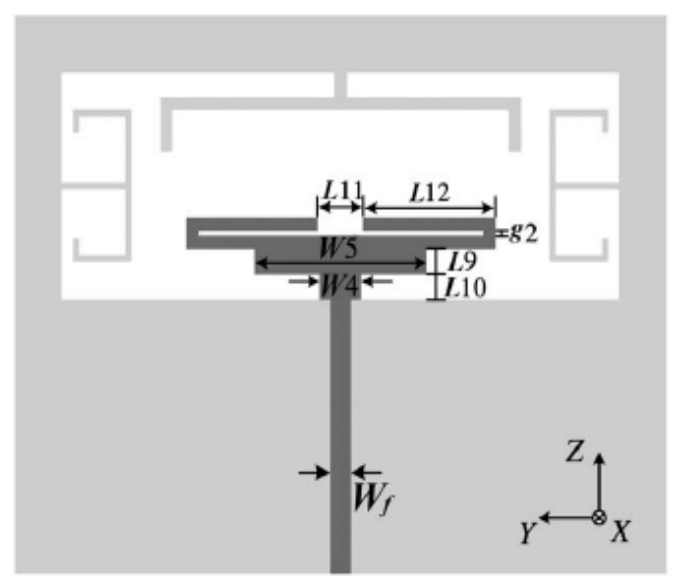

(b) Bottom view

Fig. 1. Geometry of the proposed penta-band antenna

The antenna can generate five resonant frequencies at 1.5 $\mathrm{GHz}, 2.2 \mathrm{GHz}, 3.1 \mathrm{GHz}, 4.2 \mathrm{GHz}$ and $5.3 \mathrm{GHz}$. These frequencies cover different wireless standards including LTE/4G/5G, WiBro/WiMax, Satcomm and WLAN. The rectangular slot and inverted $\mathrm{T}$-shaped stub together generate 
the first frequency of $1.5 \mathrm{GHz}$. The two E-shaped stubs etched in the rectangular slot act like a monopole and generate resonance at $2.2 \mathrm{GHz}$. The third frequency of $3.1 \mathrm{GHz}$ is generated by the $\mathrm{T}$-shaped feeding patch and inverted $\mathrm{T}$ shaped stub etched in the rectangular slot. The extended Eshaped stub and I-shaped stub together produces the fourth resonance at $4.2 \mathrm{GHz}$. The T-shaped feeding patch at its own generates the fifth resonance frequency at $5.3 \mathrm{GHz}$.

\section{RESULTS AND ANALYSIS}

The performance of the proposed antenna is analysed in terms of its $S_{11}$ response, radiation patterns, efficiency and gain.

\section{A. $S_{11}$ Response}

Fig. 2 shows the $S_{11}$ response of the proposed antenna. The antenna is resonating at five frequencies including $\mathrm{f}_{1}=1.5 \mathrm{GHz}$, $\mathrm{f}_{2}=2.2 \mathrm{GHz}, \mathrm{f}_{3}=3.1 \mathrm{GHz}, \mathrm{f}_{4}=4.2 \mathrm{GHz}$ and $\mathrm{f}_{5}=5.3 \mathrm{GHz}$. A very good impedance match is being observed at the five operating frequencies. For $1.5 \mathrm{GHz}$ band, the $\mathrm{S}_{11}$ is noted to be $-20.46 \mathrm{~dB}$ with a $-10 \mathrm{~dB}$ impedance bandwidth of 68.2 $\mathrm{MHz}$ (from $1.42 \mathrm{GHz}$ to $1.49 \mathrm{GHz}$ ). For the second resonance at $2.2 \mathrm{GHz}, \mathrm{S}_{11}$ is observed to be $-29.49 \mathrm{~dB}$. The $-10 \mathrm{~dB}$ impedance bandwidth of $99.7 \mathrm{MHz}$ covers frequencies from $2.16 \mathrm{GHz}$ to $2.26 \mathrm{GHz}$. At $\mathrm{f}_{3}=3.1 \mathrm{GHz}, \mathrm{S}_{11}$ is $-11.82 \mathrm{~dB}$ and the antenna covers frequencies from $3.03 \mathrm{GHz}$ to $3.23 \mathrm{GHz}$ having a bandwidth of $197.8 \mathrm{MHz}$. At $\mathrm{f}_{4}=4.2 \mathrm{GHz}, \mathrm{S}_{11}$ is $11.44 \mathrm{~dB}$ while the antenna operates between the frequencies of $3.98 \mathrm{GHz}$ and $4.37 \mathrm{GHz}$ for $-10 \mathrm{~dB}$ impedance bandwidth of $389.9 \mathrm{MHz}$. The antenna exhibits a $\mathrm{S}_{11}$ of $-25.21 \mathrm{~dB}$ at the fifth resonance frequency of $\mathrm{f}_{5}=5.3 \mathrm{GHz}$. The $-10 \mathrm{~dB}$ impedance bandwidth is $135.61 \mathrm{MHz}$ covering a range from $5.33 \mathrm{GHz}$ to $5.46 \mathrm{GHz}$.

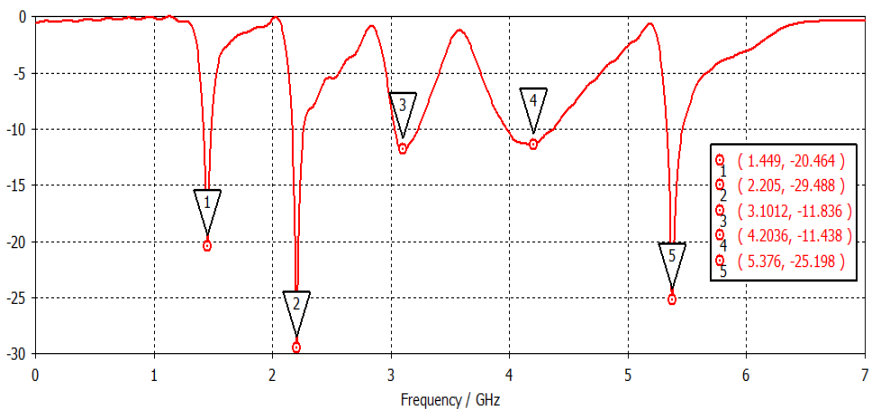

Fig. 2. $\mathrm{S}_{11}$ response of the proposed antenna

\section{B. Radiation Characteristics}

The radiation characteristics of the antenna are analysed in terms of 3-D simulated radiation patterns at the five operating frequencies. Fig. 3 illustrates the observed 3-D radiation patterns at the five resonance frequencies. The 3-D radiation patterns show that at the four lower frequencies, the direction of radiation is perpendicular to the plane of antenna.

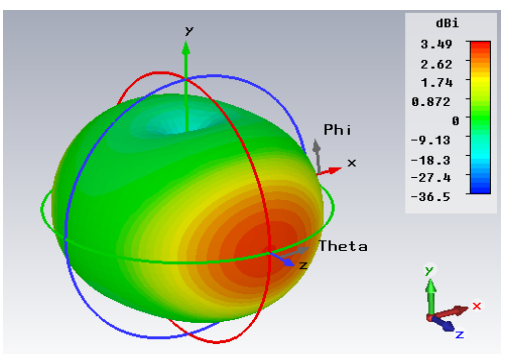

(a) $f_{1}=1.5 \mathrm{GHz}$

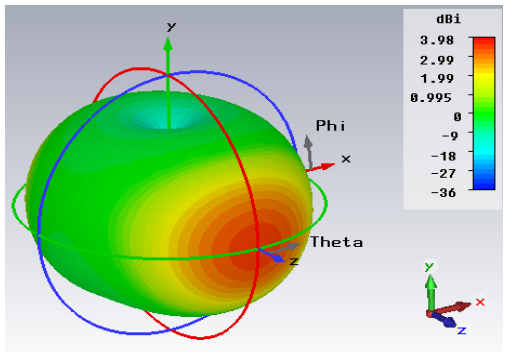

(b) $\mathrm{f}_{2}=2.21 \mathrm{GHz}$

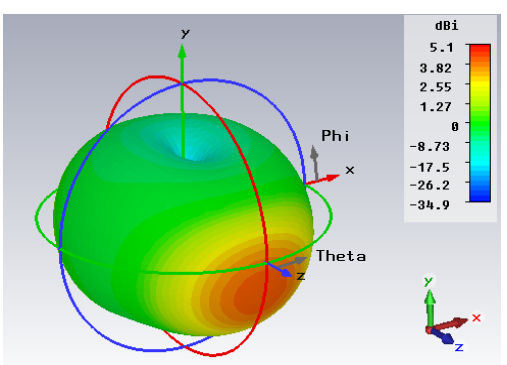

(c) $f_{3}=3.1 \mathrm{GHz}$

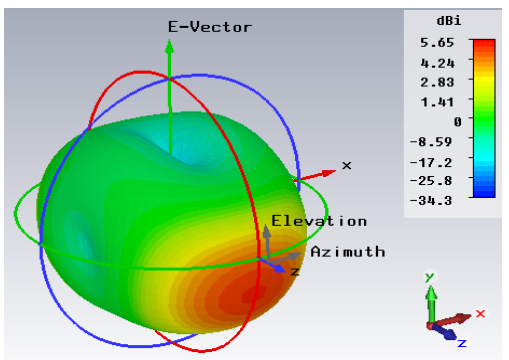

(d) $\mathrm{f}_{4}=4.2 \mathrm{GHz}$

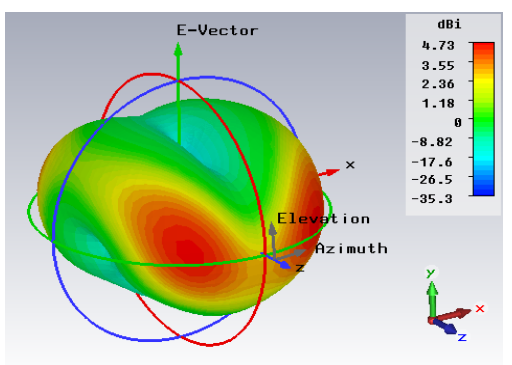

(e) $\mathrm{f}_{5}=5.3 \mathrm{GHz}$

Fig. 3. Simulated 3-D radiation patterns of the proposed antenna at the five operating frequencies 
At these frequencies, the antenna exhibits a nearly omnidirectional radiation pattern in the $\mathrm{x}-\mathrm{y}$ plane while in the $\mathrm{x}-\mathrm{z}$ plane, the antenna has a dumbbell-shaped radiation pattern. At $\mathrm{f}_{5}=5.3 \mathrm{GHz}$, the direction of radiation is 45 degrees to the plane of antenna on both sides. The $3 \mathrm{~dB}$ angular width is 88.2 , $85.8,74,44$ and 33 degrees at the five frequencies, respectively.

\section{Efficiency and Gain}

The simulated radiation efficiencies of the proposed antenna at the five operating bands are shown in Fig. 4. The antenna has good efficiency profile having a minimum efficiency value of $81 \%$ at frequency $1.5 \mathrm{GHz}$ and maximum value of $95 \%$ at frequency $2.2 \mathrm{GHz}$. At $\mathrm{f}_{3}=3.1 \mathrm{GHz}$, the antenna exhibits an efficiency of $87 \%$ while at $\mathrm{f}_{4}=4.2 \mathrm{GHz}$, it is $95 \%$. At $\mathrm{f}_{5}=5.3 \mathrm{GHz}$, the efficiency value is noted to be $92 \%$.

The simulated gain of the antenna is illustrated in Fig. 5. The gain values are observed to be $3.5 \mathrm{dBi}$ at $1.5 \mathrm{GHz}, 3.9$ dBi at $2.2 \mathrm{GHz}, 5.1 \mathrm{dBi}$ at $3.1 \mathrm{GHz}, 5.7 \mathrm{dBi}$ at $4.2 \mathrm{GHz}$ and $4.7 \mathrm{dBi}$ at $5.3 \mathrm{GHz}$. These values show that this antenna also presents an excellent gain profile at all the operational frequencies.

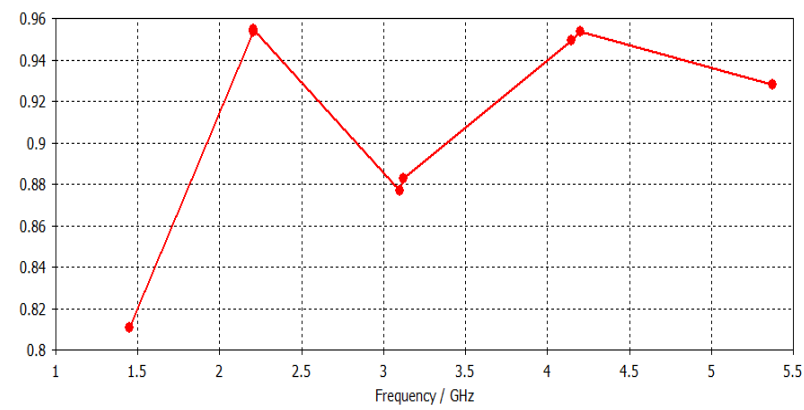

Fig. 4. Simulated radiation efficiency of the proposed antenna at the five operating frequencies

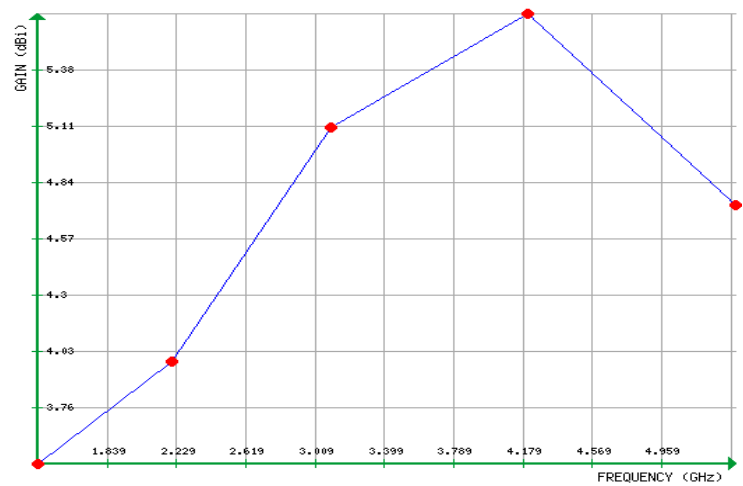

Fig. 5. Simulated gain of the proposed antenna at the five operating frequencies

\section{CONCLUSION AND FUTURE WORK}

A novel multiband antenna has been designed, analysed, and discussed. The proposed multiband antenna can resonate at five frequencies in the range from $1 \mathrm{GHz}$ to $6 \mathrm{GHz}$ to support LTE/4G/5G, WiBro/WiMax, Satcomm and WLAN operation at $1.5 \mathrm{GHz}, 2.2 \mathrm{GHz}, 3.1 \mathrm{GHz}, 4.2 \mathrm{GHz}$ and 5.3
GHz. It offers good radiation characteristics with high gain and efficiency values. The antenna radiates perpendicular to the plane of antenna with good half power beamwidths. The antenna has exhibited good directivity and gain values at the covered frequencies with a maximum gain of $5.65 \mathrm{dBi}$ at $5.576 \mathrm{GHz}$. A good impedance matching and acceptable impedance bandwidth has been observed. These along with a small size make the antenna a very suitable candidate for the portable wireless applications. Its small size also makes it a potential candidate for body-centric wireless communications.

\section{REFERENCES}

[1] David A. Sánchez-Hernández, "Multiband Integrated Antennas for 4G Terminals", Artech House, 2008, ISBN: 978-1596933989.

[2] Mohammad A. Matin (Ed.), "Wideband, Multiband, and Smart Reconfigurable Antennas for Modern Wireless Communications", Idea Group (US), 2015, ISBN: 978-1466686458.

[3] Debatosh Guha and Yahia M.M. Antar (Ed.), "Microstrip and Printed Antennas: New Trends, Techniques and Applications", John Wiley \& Sons, 2011, ISBN: 978-1119972983.

[4] Zhi Ning Chen (Editor), “Antennas for Portable Devices", John Wiley \& Sons, 2007, ISBN: 978-0470030738.

[5] Neeraj Rao and Dinesh Kumar V., "Gain and Bandwidth Enhancement of a Microstrip Antenna Using Partial Substrate Removal in Multiplelayer Dielectric Substrate," Progress In Electromagnetics Research Symposium, pp. 1285-1289, 2011.

[6] Sun, X.L.; Cheung, S.W.; Yuk, T.I., "Dual-Band Monopole Antenna With Frequency-Tunable Feature for WiMAX Applications," IEEE Antennas and Wireless Propagation Letters, , vol. 12, pp.100-103, 2013.

[7] Viet-Anh Nguyen; Byeong-Yong Park; Seong-Ook Park; Giwan Yoon, "A Planar Dipole for Multiband Antenna Systems With Self-Balanced Impedance," IEEE Antennas and Wireless Propagation Letters, vol. 13, pp.1632-1635, 2014.

[8] Cho-Kang Hsu; Shyh-Jong Chung, "Compact Multiband Antenna for Handsets With a Conducting Edge," IEEE Transactions on Antennas and Propagation, vol. 63, no. 11, pp. 5102-5107, Nov. 2015.

[9] Chih-Hua Chang; Kin-Lu Wong, "Printed $\lambda / 8$-PIFA for Penta-Band WWAN Operation in the Mobile Phone," IEEE Transactions on Antennas and Propagation, vol. 57, no. 5, pp. 1373-1381, May 2009.

[10] He Huang; Ying Liu; Shaoshuai Zhang; Shuxi Gong, "Multiband Metamaterial-Loaded Monopole Antenna for WLAN/WiMAX Applications," IEEE Antennas and Wireless Propagation Letters, vol. 14, pp. 662-665, 2015.

[11] Yuandan Dong; Toyao, H.; Itoh, T., "Design and Characterization of Miniaturized Patch Antennas Loaded With Complementary Split-Ring Resonators," IEEE Transactions on Antennas and Propagation, vol. 60, no. 2, pp. 772-785, Feb. 2012.

[12] Ming-Tien Wu; Ming-Lin Chuang, "Multibroadband Slotted Bow-Tie Monopole Antenna," IEEE Antennas and Wireless Propagation Letters, vol. 14, pp. 887-890, 2015.

[13] Falade, O.P.; Ur-Rehman, M.; Yue Gao; Xiaodong Chen; Parini, C.G., "Single Feed Stacked Patch Circular Polarized Antenna for Triple Band GPS Receivers," IEEE Transactions on Antennas and Propagation, vol. 60, no. 10, pp. 4479-4484, Oct. 2012.

[14] Ur-Rehman, M. and Allen, B., "A Compact Multi-band Slot-ring Microstrip Patch Antenna for Wireless Applications," Antennas and Propagation Conference (LAPC), pp. 595-598, Nov. 2013.

[15] Cao, Y.F.; Cheung, S.W. and Yuk, T.I., "A Multiband Slot Antenna for GPS/WiMAX/WLAN Systems," IEEE Transactions on Antennas and Propagation, vol. 63, no. 3, pp. 952-958, 2015. 